\title{
Immunological and hematological reference intervals among HIV-seronegative pregnant women in northwest Ethiopia
}

This article was published in the following Dove Press journal:

International Journal of Women's Health

3 March 2017

Number of times this article has been viewed

\author{
Meaza Genetu' \\ Debasu Damtie' \\ Meseret Workineh' \\ Biniam Mathewos Tebeje ${ }^{1,2}$ \\ Bamlaku Enawgaw ${ }^{3}$ \\ Tekalign Deressa' \\ 'Department of Immunology \\ and Molecular Biology, School of \\ Biomedical and Laboratory Sciences, \\ College of Medicine and Health \\ Science, University of Gondar, Gondar, \\ Ethiopia; ${ }^{2}$ Molecular Parasitology \\ Laboratory, Queensland Institute of \\ Medical Research, Brisbane, Australia; \\ ${ }^{3}$ Department of Hematology and \\ Immunohematology, School of \\ Biomedical and Laboratory Sciences, \\ College of Medicine and Health \\ Science, University of Gondar, Gondar, \\ Ethiopia
}

Correspondence: Tekalign Deressa Department of Immunology and Molecular Biology, School of Biomedical and Laboratory Sciences, College of Medicine and Health Science, University of Gondar, PO Box 196, Gondar, Ethiopia

Email tekalign09@gmail.com
Background: Pregnancy is a state characterized by profound physiological hematological changes. However, hematological reference intervals being used in clinical practice in Ethiopia are derived from nonlocal general populations, despite the significant variations reported previously. The aim of this study was to determine the immunological and hematological reference intervals in healthy pregnancy among HIV-seronegative pregnant women in northwest Ethiopia.

Materials and methods: A total of 200 healthy, HIV-seronegative pregnant women were enrolled from February 2015 to June 2015 in a cross-sectional study setting at Gondar University Hospital. Sociodemographic and obstetric data were collected using a structured questionnaire. Blood samples collected from each participant were used to define the immunological and hematological parameters. The mean, median, and 95\% interval values were calculated for the immunological and hematological parameters. $P$-value $<0.05$ was considered statistically significant for all variables.

Results: This study found that there were changes in CD4+ T-cell count, platelet count, and hematocrit (HCT) values as pregnancy advances. The calculated combined reference intervals for the absolute CD4+ T-cell count and platelet count were 712.47-760.67 and 221.25-240.14, respectively. A progressive decline in the platelet count was observed as pregnancy advanced, with 95\% intervals of 224.53-253.21, 209.50-237.38, and 213.70-247.86 in the first, second, and third trimesters, respectively $(P=0.27)$. There was a statistically significant increase in mean ( \pm standard deviation [SD]) HCT with gestational age, being 39.18 $\pm 6.70,41.96 \pm 3.70$, and $40.53 \pm 3.77$ in the first, second, and third trimesters, respectively $(P=0.03)$. The overall $95 \%$ interval for hemoglobin (HB) concentration was $12.99-13.36 \mathrm{~g} / \mathrm{dL}$, HCT $40.19 \%-41.49 \%$, mean corpuscular volume (MCV) 93.33-94.63 fL, and mean corpuscular hemoglobin (MCH) 28.88-34.81 pg. Compared with the reference ranges derived from other studies, we found considerable variations in CD4+ T-cell count, HB, HCT, and MCV values.

Conclusion: The findings of this study highlight the differences in immunohematological profile among pregnant women and nonpregnant women from Ethiopia and other countries, in addition to suggesting the need for such establishment of local reference values for different populations.

Keywords: immunological parameter, hematological parameter, pregnant women, reference range, immunohematological reference intervals

\section{Introduction}

Hematological and immunological reference intervals play a critical role as clinical guides in the diagnosis or monitoring of several diseases as well as adverse reactions during clinical trials. ${ }^{1,2}$ These parameters have been reported to vary by age, sex, pregnancy, dietary patterns, genetic background, and geographical factors. ${ }^{3-5}$ For example, 
Ethiopian populations have been reported to have high hemoglobin (HB) and hematocrit (HCT) levels when compared to some African countries and Western populations. ${ }^{6,7}$ On the other hand, they have lower CD4+ T-cell counts and CD4+/ CD8+ T-cell ratios. ${ }^{7}$ The Clinical and Laboratory Standards Institute (CLSI) recommends that each laboratory establish its own reference intervals for proper interpretation of laboratory test results. However, many African countries are still relying on reference values obtained from textbooks based on nonlocal populations.

Immunohematological reference intervals among different segments of the Ethiopian population are poorly defined. Although few studies have been conducted in Ethiopia to determine the immunological as well as hematological reference intervals for the general population, there is scarcity of data on reference intervals for pregnant women. ${ }^{6,7}$ Pregnancy is a state characterized by profound hematological changes, such as changes in HB concentration, platelet (PLT) count, as well as red blood cell (RBC) and white blood cell (WBC) counts. ${ }^{8-10}$ The use of reference intervals derived from general non-Ethiopian populations could lead to misinterpretation of the laboratory test results and may allow incorrect clinical care for this group of the population. Hence, it is mandatory to establish local immunohematological reference intervals for pregnant women. This would be especially useful during antiretroviral therapy (ART) initiation and treatment follow-up of HIV-positive pregnant women. In addition, this study is of importance because an attempt to predict and/or improve pregnancy outcome during antenatal care are also dependent on immunohematological indexes.

The aim of this study was to establish the immunological and hematological reference intervals of healthy and HIVseronegative pregnant women in Northwest Ethiopia. In addition, it compared the reference values obtained from this study with previously reported values from different countries.

\section{Materials and methods}

\section{Study settings, population, and period}

In this study, 200 healthy HIV-negative pregnant women attending the antenatal clinic (ANC) were included. Only pregnant women with body mass indexes within the normal range were enrolled into the study. The study was conducted at the University of Gondar Teaching Hospital, Gondar, Northwest Ethiopia, in a cross-sectional setting. Gondar is located at $737 \mathrm{~km}$ from the country's capital Addis Ababa in the North Gondar zone of the Amhara regional state. The city has latitude and longitude of $12^{\circ} 03^{\prime} 61^{\prime \prime} \mathrm{N}$ and $37^{\circ} 02^{\prime} 81^{\prime \prime} \mathrm{E}$, respectively and an elevation of 2,133 $\mathrm{m}$ above sea level. The study was conducted between February 2015 and June 2015.

\section{Data collection}

Sociodemographic and obstetric characteristics of the study participants were collected using a structured questionnaire. Variables such as age, marital status, educational status, occupation, gestational age, smoking habit, and alcohol use were collected.

\section{Laboratory methods}

Approximately $4 \mathrm{~mL}$ of venous blood was collected from each study participant in the morning from 8:00 am to 11:00 am and processed within 3 hours of collection. Hematological parameters were determined by a Cell-Dyn ${ }^{\circledR} 1800$ (Abbott Laboratories, Chicago, IL, USA) which was standardized against a $4 \mathrm{C}^{\circledR}$ Plus blood control. The immunological parameters were analyzed using the BD FACSCount ${ }^{\mathrm{TM}}$ system (Becton Dickinson, San Jose, CA, USA). The performance of the instruments was controlled by running control samples prior to the start of the test.

HIV infection was detected using rapid HIV-1/2 test kits as per the national algorithm for HIV testing. Briefly, whole-blood samples were screened for HIV using a KHB diagnostic kit (Shanghai Kehua Bio-engineering Co Ltd, China). Reactive samples were confirmed using Stat-Pak ${ }^{\circledR}$ (Chembio Diagnostics, Medford, NY, USA) and Uni-Gold ${ }^{\mathrm{TM}}$ kits (Trinity Biotech, Bray, Wicklow, Ireland) according to the national algorithm for HIV testing.

\section{Statistical analysis}

Data were checked for completeness and entered using SPSS version 20 software (IBM Corporation, Armonk, NY, USA) for analysis. A descriptive analysis was used to summarize the sociodemographic and clinical characteristics of the study participants. Reference intervals were computed using the nonparametric method. The mean, median, and standard deviation (SD) values were calculated for each immunohematological parameter. The 95th percentile reference intervals were determined. Analysis of variance (ANOVA) was used for any statistically significant difference in these parameters in relation to the age and trimesters of the study participants. $P$-values $<0.05$ were considered statistically significant for all variables.

\section{Ethical considerations}

Ethical clearance was obtained from the institutional ethical review board of the University of Gondar. A permission 
letter was also obtained from the hospital's clinical director to conduct the study. After explaining the objectives of the study, written informed consent was obtained from each study participant. In cases of participants who were unable to read and write, a finger print was obtained as a signature in presence of literate witnesses. The interviews with study participants were conducted with strict privacy, and their data were handled with assurance of confidentiality.

\section{Results}

\section{Demographic and obstetric characteristics}

A total of 200 pregnant women were enrolled in this study. The age range of the participants was 18-42 years. Seventytwo $(36 \%)$ participants were younger than 24 years, 111 (55.5\%) were between 25 and 33 years, and 17 (8.5\%) were between 34 and 42 years. Almost all (99.5\%) of the women were married, and $103(51.5 \%)$ of them were multigravidae. In terms of their gestational age, $34.5 \%$ and $43 \%$ of the study participants were on their second and third trimesters, respectively. All of the participants reported no smoking and no alcohol use (Table 1).

Table I Sociodemographic and behavioral characteristics of HIVI/2-negative pregnant women who visited the ANC clinic of the University of Gondar Hospital, NW Ethiopia, 2015

\begin{tabular}{|c|c|c|}
\hline $\begin{array}{l}\text { Sociodemographic and } \\
\text { behavioral characteristics }\end{array}$ & Number & Percentage \\
\hline \multicolumn{3}{|l|}{ Age, years } \\
\hline$\leq 24$ & 72 & 36 \\
\hline $25-33$ & II I & 55.5 \\
\hline $34-42$ & 17 & 8.5 \\
\hline \multicolumn{3}{|l|}{ Marital status } \\
\hline Married & 199 & 99.5 \\
\hline Single & I & 0.5 \\
\hline \multicolumn{3}{|l|}{ Educational status } \\
\hline Illiterate & 37 & 18.5 \\
\hline Primary education & 27 & 13.5 \\
\hline Secondary education & 82 & 41 \\
\hline Tertiary education & 54 & 27 \\
\hline \multicolumn{3}{|l|}{ Gestational age } \\
\hline First trimester & 45 & 22.5 \\
\hline Second trimester & 69 & 34.5 \\
\hline Third trimester & 86 & 43 \\
\hline \multicolumn{3}{|l|}{ Gravidity } \\
\hline Primigravida & 97 & 48.5 \\
\hline Multigravida & 103 & 51.5 \\
\hline \multicolumn{3}{|l|}{ Smoking habit } \\
\hline Yes & 0 & 0 \\
\hline No & 200 & 100 \\
\hline \multicolumn{3}{|l|}{ Alcohol use } \\
\hline Yes & 0 & 0 \\
\hline No & 200 & 100 \\
\hline
\end{tabular}

Abbreviations: ANC, antenatal clinic; NW, Northwest.

\section{Immunological parameters}

The mean, median, and 95\% reference values stratified by gestational age for absolute CD4+ T-cell count, percentage CD4+ T-cell count, lymphocytes and total WBC counts are summarized in Table 2 . The overall mean $( \pm \mathrm{SD}) \mathrm{CD} 4+$ T-cell count was $738 \pm 173$, while the percentage CD4+ T-cell count was $39.53 \pm 6.82$, mean lymphocytes count was

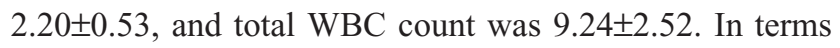
of their gestational age, the minimum mean $( \pm S D)$ value for absolute CD4+ T-cell count (728 \pm 171$)$ was observed among women in the second trimester of their pregnancy, whereas the maximum $(758 \pm 218)$ was observed among the women in the first trimester of pregnancy. Percentage CD4+ T-cell counts (median) in the first, second, and third trimesters of the pregnant women were 38.82, 40.18, and 39.60, respectively. The calculated combined reference intervals for total lymphocytes were $2.18-2.53,1.96-2.22$, and $2.11-2.33$ in the first, second, and third trimesters, respectively.

Except for lymphocyte count, which was significantly lower among women at the second trimester $(P<0.05)$, no significant difference between various WBC subset values was observed with the age and gestational age of the women $(P>0.05)$.

\section{Hematological parameters}

Table 3 shows the mean values, medians, and 95 th percentile reference intervals according to gestational age for different hematological parameters. The mean PLT and RBC counts of the study participants were $230.70 \pm 67.74$ and $4.37 \pm 0.49$, respectively. The overall mean value for $\mathrm{HB}$ concentration was $13.2 \pm 1.3 \mathrm{~g} / \mathrm{dL}$, HCT level was $40.8 \% \pm 4.7 \%$, MCV was 93.98 $\pm 4.64 \mathrm{fL}$, mean corpuscular hemoglobin $(\mathrm{MCH})$ was $30.36 \pm 2.41 \mathrm{pg}$, and mean corpuscular hemoglobin concentration (MCHC) was $32.63 \pm 5.23 \mathrm{~g} / \mathrm{dL}$.

There was no statistically significant difference in PLT count, RBC count, HB level, MCV, MCH, and MCHC of the pregnant women with their gestation age $(P>0.05)$. However, PLT count showed a decreasing trend with gestational age. With respect to HCT values, a statistically significant difference $(P=0.033)$ was observed between different trimesters, with the lowest value observed among the women in the first trimester of pregnancy.

\section{Discussion}

Clinical laboratory reference intervals are essential for accurate interpretation of laboratory results, and they guide patient care and treatment. Furthermore, some of these values, such as the CD4+ T-cell count, are used as surrogate 
Table 2 Mean value, median, and 95\% reference interval for immunological parameters among HIV-negative pregnant women who visited the ANC of the University of Gondar Hospital, NW Ethiopia, 2015

\begin{tabular}{|c|c|c|c|c|}
\hline Gestational age & $\begin{array}{l}\text { Absolute CD4 + T cell } \\
\text { count } / \mu \mathrm{L}\end{array}$ & $\begin{array}{l}\text { CD4 }+\mathrm{T} \text { cell } \\
\text { count }\end{array}$ & Lymphocyte count, $\times 10^{3} / \mu \mathrm{L}$ & Total WBC count, $\times 10^{3} / \mu \mathrm{L}$ \\
\hline \multicolumn{5}{|c|}{ First trimester $(n=45)$} \\
\hline Mean \pm SD & $758 \pm 218$ & $39.12 \pm 6.72$ & $2.36 \pm 0.58^{*}$ & $9.46 \pm 2.80$ \\
\hline Median & 750 & 38.82 & 2.30 & 9.00 \\
\hline $95 \%$ range & $692.02-822.74$ & $37.12-41.14$ & $2.18-2.53$ & $8.62-10.30$ \\
\hline \multicolumn{5}{|c|}{ Second trimester $(n=69)$} \\
\hline Mean \pm SD & $728 \pm|7|$ & $40.03 \pm 7.23$ & $2.09 \pm 0.52^{*}$ & $9.29 \pm 2.56$ \\
\hline Median & 711 & 40.18 & 2.10 & 9.40 \\
\hline $95 \%$ range & $683.78-765.69$ & $38.30-41.82$ & $1.96-2.22$ & $8.67-9.90$ \\
\hline \multicolumn{5}{|c|}{ Third trimester $(n=86)$} \\
\hline Mean \pm SD & $735 \pm 148$ & $39.34 \pm 6.58$ & $2.21 \pm 0.50$ & $9.10 \pm 2.36$ \\
\hline Median & 741 & 39.60 & 2.15 & 9.15 \\
\hline $95 \%$ range & 703.36-766.7I & $37.93-40.76$ & $2.11-2.33$ & $8.60-9.61$ \\
\hline \multicolumn{5}{|l|}{ Total $(n=200)$} \\
\hline Mean \pm SD & $738 \pm 173$ & $39.53 \pm 6.82$ & $2.20 \pm 0.53$ & $9.24 \pm 2.52$ \\
\hline Median & 738 & 39.57 & 2.20 & 9.05 \\
\hline $95 \%$ range & $7 \mid 2.47-760.67$ & $38.58-40.49$ & $2.13-2.28$ & $8.90-9.60$ \\
\hline$P$-value & 0.09 & 0.19 & 0.97 & 0.07 \\
\hline
\end{tabular}

Note: $* P=0.033$, post hoc test.

Abbreviations: ANC, antenatal clinic; NW, Northwest; SD, standard deviation; WBC, white blood cell.

markers for disease progression and/or in staging of diseases such as HIV infection. Even though hematological profiles of individuals reflect their general health, physiological conditions such as pregnancy are capable of causing remarkable changes. ${ }^{9-11}$ Physiologic anemia, thrombocytopenia, and neutrophilia are some of the hematological changes reported during normal pregnancy. Despite these changes, many African countries, including Ethiopia, lack reference intervals specific to pregnant women and use reference intervals derived from the Western population in clinical practice. This necessitates the establishment of local reference intervals specific to healthy pregnant women. Such reference interval has paramount significance for the care and treatment of HIV-positive pregnant women as their number is increasing as a result of the universal access to ART. The current study describes the hematological and

Table 3 Mean value, median, and 95\% reference interval for hematological parameters among HIV-negative pregnant women who visited the ANC of the University of Gondar Hospital, NW Ethiopia, 2015

\begin{tabular}{|c|c|c|c|c|c|c|c|}
\hline Gestational age & Platelet count, $\times 10^{3} / \mu \mathrm{L}$ & RBC count, $\times 10^{6} / \mu \mathrm{L}$ & HB, g/dL & Hematocrit, \% & MCV, fL & $\mathrm{MCH}, \mathrm{pg}$ & MCHC, g/dL \\
\hline \multicolumn{8}{|c|}{ First trimester $(n=45)$} \\
\hline Mean \pm SD & $243.87 \pm 64.38$ & $4.27 \pm 0.62$ & $12.94 \pm 1.70$ & $39.18 \pm 6.70^{*}$ & $93.18 \pm 3.87$ & $30.48 \pm 2.20$ & $32.70 \pm 2.27$ \\
\hline Median & 255.00 & 4.29 & 13.00 & 40.30 & 93.40 & 30.20 & 32.30 \\
\hline $95 \%$ range & $224.53-253.21$ & $4.08-4.46$ & $12.43-13.46$ & $37.17-41.19$ & $92.02-94.34$ & $29.82-31.14$ & $37.02-33.38$ \\
\hline \multicolumn{8}{|c|}{ Second trimester $(n=69)$} \\
\hline Mean \pm SD & $230.78 \pm 71.09$ & $4.32 \pm 0.46$ & $13.07 \pm 1.05$ & $40.53 \pm 3.77$ & $94.19 \pm 4.21$ & $30.47 \pm 2.64$ & $33.29 \pm 8.55$ \\
\hline Median & 230.00 & 4.33 & 13.00 & 40.80 & 93.90 & 30.40 & 32.10 \\
\hline $95 \%$ range & $213.70-247.86$ & $4.21-4.43$ & $12.82-13.33$ & $39.63-41.44$ & $93.18-95.20$ & $29.84-31.11$ & $31.24-35.35$ \\
\hline \multicolumn{8}{|c|}{ Third trimester $(n=86)$} \\
\hline Mean \pm SD & $223.74 \pm 66.42$ & $4.46 \pm 0.43$ & $13.38 \pm 1.25$ & $41.96 \pm 3.70 *$ & $94.23 \pm 5.30$ & $30.21 \pm 2.33$ & $32.08 \pm 1.53$ \\
\hline Median & 224.00 & 4.42 & 13.45 & 41.70 & 93.95 & 30.00 & 32.00 \\
\hline $95 \%$ range & $209.50-237.38$ & $4.37-4.55$ & $13.11-13.67$ & $41.17-42.75$ & $93.09-95.37$ & $26.73-40.79$ & $31.75-32.41$ \\
\hline \multicolumn{8}{|l|}{ Total $(n=200)$} \\
\hline Mean \pm SD & $230.70 \pm 67.74$ & $4.37 \pm 0.49$ & $13.2 \pm 1.3$ & $40.8 \pm 4.7$ & $93.98 \pm 4.64$ & $30.36 \pm 2.4 \mathrm{I}$ & $32.63 \pm 5.23$ \\
\hline Median & 230.00 & 4.36 & 13.2 & 40.9 & 93.7 & 30.2 & 32 \\
\hline $95 \%$ range & $221.25-240.14$ & $4.30-4.44$ & $12.99-13.36$ & $40.19-41.49$ & $93.33-94.63$ & $28.88-34.81$ & $31.91-33.37$ \\
\hline
\end{tabular}

Note: $* P=0.03$ as determined by ANOVA.

Abbreviations: ANC, antenatal clinic; ANOVA, analysis of variance; $\mathrm{HB}$, hemoglobin; $\mathrm{MCH}$, mean corpuscular hemoglobin; $\mathrm{MCHC}$, mean corpuscular hemoglobin concentration; MCV, mean cell volume; NW, Northwest; RBC, red blood cell; SD, standard deviation. 
immunological reference intervals among HIV-seronegative pregnant women in Northwest Ethiopia, where HIV prevalence is higher than $10 \%$, albeit the low national HIV prevalence rate $(1.14 \%) .{ }^{12-14}$

In this study, a decline in the number of CD4+ T-cell count was observed as pregnancy advances. This reduction in CD4+ T-cell count could be associated with the increase in hormones such as progesterone and estrogen, which suppress the maternal immune system to avoid rejection of the fetus. This finding was in agreement with the results of a number of previous studies. ${ }^{15,16}$ Moreover, the reference interval found in this study for absolute CD+ T-cell count (712.47-760.67) was within the range in other studies from Ethiopia (456-1,368), Mozambique (434-1,479), and Kenya (440-1,602) (range is an estimate of the $95 \%$ confidence limits). ${ }^{7,17,18}$ The mean WBC count observed in this study was higher than that in the study by Miri-Dashe et al ${ }^{15}$ among Nigerian pregnant women (9.24 vs 6.62). Similarly, the $95 \%$ interval of the WBC count among Ethiopian pregnant women was higher than that of Nigerian pregnant women. But, it was within the range of the US-based reference value. ${ }^{19}$ This finding supports the hypothesis that genetic factors could determine individuals' CD4+ count. However, factors such as study design, presence of specific infection, and general nutritional status might also contribute to such discrepancies.

RBCs, HB, and HCT values were slightly higher in our study than in the US-based comparison intervals, possibly because of the higher altitude and dietary factors in Ethiopia. ${ }^{19}$ But, these were lower than the values in healthy, HIV-uninfected Ethiopian population. ${ }^{7}$ This is ascribed to the transient changes in the hematological profile of the women due to pregnancy. Similar findings have previously been observed in terms of a reduction in the RBC indexes among pregnant women. ${ }^{15}$ While the mean values for MCV and $\mathrm{MCH}$ in this study were higher than those of a similar study from Nigeria, ${ }^{15}$ the MCHC value was considerably lower than that of their Nigerian counterparts $(32.63 \pm 5.23$ vs $36.45 \pm 1.10)$. Taken together, these findings underscore the need for establishing local reference intervals specific to the population under study for routine clinical practice.

Thrombocytopenia, defined as a PLT count $<150,000 \times 10^{9} / \mathrm{L}$, is one of the common hematological abnormalities during pregnancy. This study showed that the PLT count among the study participants was within the normal range, despite a progressive reduction in PLT count as pregnancy advanced. This was in agreement with previously published studies. ${ }^{20,21}$ PLT count has been reported to decrease by up to $10 \%$ in normal pregnancy, with most of the decrease occurring during the third trimester due to hemodilution resulting from an increase in plasma volume.

This study has some limitations in that we could not include pregnant women with no iron supplementation as a control group because of issues related to ethics. Furthermore, the majority of our study participants were highlanders from Gondar area, and they were predominantly from the Amhara ethnic group. Thus, the findings of this study may not apply to other ethnic groups who specially dwell in the lowland areas. Nevertheless, the reference intervals established in this study provide useful information for health care personnel and researchers in this specific area.

\section{Conclusion}

The laboratory reference intervals established by this study are one of the comprehensive immunohematological reference intervals specific to pregnant women in Northwest Ethiopia. The findings of this study highlight the differences in immunohematological profiles among pregnant women and nonpregnant women from Ethiopia and across countries and suggest the need for such establishment of local reference values for different populations.

\section{Acknowledgments}

We are very grateful to the University of Gondar Teaching Hospital ANC clinic staffs, counseling nurses, and diagnostic laboratory staffs for their kind cooperation during data collection. We would also like to extend our gratitude to all the study participants for volunteering to participate in this study.

\section{Author contributions}

MG, DD, TD, and MW participated in designing the study, performing the data collection, and statistical analysis. BMT and BE participated in the study design and data collection, as well as helping in drafting the paper. TD wrote the manuscript. All authors contributed toward data analysis, drafting and critically revising the paper and agree to be accountable for all aspects of the work.

\section{Disclosure}

The authors report no conflicts of interest in this work.

\section{References}

1. Kibaya RS, Bautista CT, Sawe FK, et al. Reference ranges for the clinical laboratory derived from a rural population in Kericho, Kenya. PLoS One. 2008;3(10):e3327.

2. Tugume SB, Piwowar EM, Lutalo T, et al. Hematological reference ranges among healthy Ugandans. Clin Diagn Lab Immunol. 1995;2(2): 233-235.

3. Bain BJ. Ethnic and sex differences in the total and differential white cell count and platelet count. J Clin Pathol. 1996;49(8):664-666. 
4. Azikiwe AN. Platelet count values in healthy Nigeria medical students in Jos. East Afr Med J. 1984;61(6):482-485.

5. Badenhorst CJ, Fourie J, Steyn K, et al. The haematological profile of urban black Africans aged 15-64 years in the Cape Peninsula. East Afr Med J. 1995;72(1):19-24.

6. Peters WH. Haematocrit and haemoglobin levels in adult males and in pregnant and non-pregnant females in northern Ethiopia. Ethiop Med J. 1984;22(1):17-27.

7. Tsegaye A, Messele T, Hailu E, et al. Immunohematological reference ranges for adult Ethiopians. Clin Diagn Lab Immunol. 1999;6(3): $410-414$.

8. Shen C, Jiang YM, Shi H, et al. A prospective, sequential and longitudinal study of haematological profile during normal pregnancy in Chinese women. J Obstet Gynaecol. 2010;30(4):357-361.

9. Cabaniss CD, Cabaniss ML. Physiologic hematology of pregnancy. In: Kitay DZ, editor. Hematologic Problems in Pregnancy. Oradell, NJ: Medical Economics; 1987:3-14.

10. Pitkin RM, White DL. Platelet and leukocyte counts in pregnancy. JAMA. 1979;243(24):2696-2698.

11. Patrick CII, Juliet J, Rita NII, Oberhiri LE. Changes in hematological indices in normal pregnancy. Physiol J. 2013;2013:4.

12. Endris M, Deressa T, Belyhun Y, Moges F. Seroprevalence of syphilis and human immunodeficiency virus infections among pregnant women who attend the University of Gondar teaching hospital, Northwest Ethiopia: a cross sectional study. BMC Infect Dis. 2014;15:111.

13. Melku M, Kebede A, Addis Z. Magnitude of HIV and syphilis seroprevalence among pregnant women in Gondar, Northwest Ethiopia: a cross-sectional study. HIV AIDS (Auckl). 2015;7:175-182.
14. WHO [webpage on the Internet]. World Health Organization Regional Office for Africa: HIV/AIDS in Ethiopia. Available from: http://www. afro.who.int/en/ethiopia/country-programmes/topics/4480-hivaids. html. Accessed January 20, 2017.

15. Miri-Dashe T, Osawe S, Tokdung M, et al. Comprehensive reference ranges for hematology and clinical chemistry laboratory parameters derived from normal Nigerian adults. PLoS One. 2014;9(5):e93919.

16. Heffron R, Donnell D, Kiarie J, et al. A prospective study of the effect of pregnancy on CD4 counts and plasma HIV-1 RNA concentrations of antiretroviral-naïve HIV-1 infected women. J Acquir Immune Defic Syndr. 2014;65(2):231-236.

17. Tembe N, Joaquim O, Alfai E, et al. Reference values for clinical laboratory parameters in young adults in Maputo, Mozambique. PLoS One. 2014;9(5):e97391.

18. Zeh C, Amornkul PN, Inzaule S, et al. Population-based biochemistry, immunologic and hematological reference values for adolescents and young adults in a rural population in Western Kenya. PLoS One. 2011;6(6):e21040.

19. Cunninghan FG. Laboratory values in normal pregnancy. In: Queenan JT, Hobbins JC, Spong CY, editors. Protocol for High Risk Pregnancies: An Evidence Based Approach. Wiley-Blackwell; 2010: 587-595.

20. Akinbami AA, Ajibola SO, Rabiu KA, et al. Hematological profile of normal pregnant women in Lagos, Nigeria. Intl J Womens Health. 2013; 5:227-232.

21. Akingbola TS, Adewole IF, Adesina OA, et al. Haematological profile of healthy pregnant women in Ibadan, south-western Nigeria. J Obstet Gynaecol. 2006;26(8):763-769.
International Journal of Women's Health

\section{Publish your work in this journal}

The International Journal of Women's Health is an international, peerreviewed open-access journal publishing original research, reports, editorials, reviews and commentaries on all aspects of women's healthcare including gynecology, obstetrics, and breast cancer. The manuscript management system is completely online and includes

\section{Dovepress}

a very quick and fair peer-review system, which is all easy to use. Visit http://www.dovepress.com/testimonials.php to read real quotes from published authors. 